\title{
Visual Literacy and Biochemistry Learning: The role of external representations
}

$$
\text { Santos, V.J.S.V. }{ }^{1,2} \text {; Galembeck, E. }{ }^{2}
$$

${ }^{1}$ Centro de Ciências da Saúde, Universidade Federal de São João Del-Rei, Minas Gerais, Brazil; ${ }^{2}$ Departamento de Bioquímica, Universidade Estadual de Campinas, São Paulo, Brazil.

Visual Literacy can be defined as people's ability to understand, use, think, learn and express themselves through external representations (ER) in a given subject. This research aims to investigate the development of abilities of ERs reading and interpretation by students from a Biochemistry graduate course of the Federal University of São João Del-Rei. In this way, Visual Literacy level was assessed using a questionnaire validated in a previous educational research. This diagnosis questionnaire was elaborated according to six visual abilities identified as essential for the study of the metabolic pathways. The initial statistical analysis of data collected in this study was carried out using ANOVA method. Results obtained showed that the questionnaire used is adequate for the research and indicated that the level of Visual Literacy related to the metabolic processes increased significantly with the progress of the students in the graduation course. There was also an indication of a possible interference in the student's performance determined by the cutoff punctuation in the university selection process.

Word Keys: Visual Literacy, Learning, Biochemistry 
This document was created with Win2PDF available at http://www.win2pdf.com. The unregistered version of Win2PDF is for evaluation or non-commercial use only. This page will not be added after purchasing Win2PDF. 